\title{
FRACTURE BEHAVIOR OF 34CrMO4 STEEL IN HIGH-PRESSURE HYDROGEN ENVIRONMENT
}

\author{
${ }^{1}$ Petr ČIZŽEK, 'Ladislav KANDER \\ ${ }^{1}$ MATERIAL AND METALLURGICAL RESEARCH Ltd., Ostrava, Czech Republic, EU, \\ petr.cizek@mmvyzkum.cz
}

https://doi.org/10.37904/metal.2020.3526

\begin{abstract}
Structural steel $34 \mathrm{CrMo} 4$ is frequently used for producing of hydrogen cylinders. For selecting material of cylinder is very important to know fatigue and fracture behavior of material directly in hydrogen environment, especially from the point of view of safety during operation. Submitted paper summarizes test results of fracture toughness measurement at static loading measured in pure hydrogen environment at pressure $15 \mathrm{MPa}$. Experiments in hydrogen environment were performed in hydrogen autoclave developed by MATERIAL AND MATERIAL RESEARCH Ltd. Test method was chosen in accordance with ČSN EN ISO 11114-4, method B. Resistivity against unstable fracture or crack growth is measured using stepped increasing of stress intensity factor applied to a specimen. Test process was monitored by potential method. Post-test examination including fracture surface analysis using scanning electron microscope was performed for better understanding of unfavorable effect of hydrogen on crack tip of specimen. Test results confirmed significant change of fracture mechanism in comparison with fracture behavior in the air.
\end{abstract}

Keywords: Fracture toughness, hydrogen environment, potential method

\section{INTRODUCTION}

In METAL 2019 conference was presented first part of evaluation of fatigue and fracture behavior of 34CrMo4 steel in high-pressure hydrogen environment which was focused on fatigue crack growth rate [1]. This steel is frequently used for producing of hydrogen cylinders and for the purpose of qualification of cylinder is also necessary to know fracture behavior of this steel at static loading. Moreover it belongs also to the group of steels with higher tensile strength (approximately $1000 \mathrm{MPa}$ ), therefore there is an assumption of susceptibility to hydrogen embrittlement connected with occurrence of intercrystalline fracture. Among other factors with significant effect on hydrogen embrittlement of material belong chemical composition, microstructure, nonmetallic inclusions, secondary phases and grain boundaries [2]. Three methods for evaluation of material resistance against hydrogen embrittlement are described in ČSN EN ISO 11114-4 standard [3]. This standard also specifies requirements for usability of material for hydrogen cylinders producing. For experimental program was chosen an approach specified by method $B$, where is material resistance against hydrogen embrittlement measured using $\mathrm{C}(\mathrm{T})$ specimens with thickness coming from wall thickness of cylinder. Precracked specimen is subsequently stepped loaded until failure. On the base of calculated values of stress intensity factor at failure and/or significant crack growth is assessed degradation of material in high pressure hydrogen environment.

\section{EXPERIMENTAL MATERIAL AND TEST METHOD}

Two sets of specimens from two heats of 34CrMo4 were used for testing. From each cylinder were machined $\mathrm{C}(\mathrm{T})$ specimens with thickness $7 \mathrm{~mm}$ and width $25 \mathrm{~mm}$. All specimens were pre-cracked with maximum value of stress intensity factor approximately $22 \mathrm{MPa} \cdot \mathrm{m}^{1 / 2}$. One specimen was at first loaded in the air in accordance 
with standard for quasistatic fracture toughness [4]. This measurement was used as a reference for comparison with experiments performed in hydrogen environment.

Whole experiments in high-pressure hydrogen environment were carried out in hydrogen autoclave built-in to servohydraulic testing machine MTS $100 \mathrm{kN}$. The autoclave with 0,5 I volume was developed and produced in MATERIAL AND METALLURGICAL RESEARCH Ltd. and can be also used without testing machine for specimen exposure in gaseous environment. Experiments were performed at pressure $15 \mathrm{MPa}$. Loading the specimens was carried out in accordance with ČSN EN ISO 11114-4 standard [3]. At first was each specimen loaded to the stress intensity factor $\mathrm{K}=20-25 \mathrm{MPa} \cdot \mathrm{m}^{1 / 2}$. After 20 minutes of loading at this stress intensity factor was applied force increased, so that stress intensity factor was increased by $1 \mathrm{MPa} \cdot \mathrm{m}^{1 / 2}$. This procedure was repeated until crack growth was detected or unstable fracture occurred.

On the specimen surface was welded electrodes for potential method. Principles of ACPD and DCPD methods and their differences were in more details described in [1]. As well as in previous experimental program was chosen a method that combines advantages of ACPD a DCPD, developed by Korec [5]. Position of electrodes on specimen surface was the same as in the case of fatigue crack growth rate. Crack growth is detected by a change of measured potentials. Figure 1 documents onset of crack extension, Figure 2 shows unstable fracture occurrence.

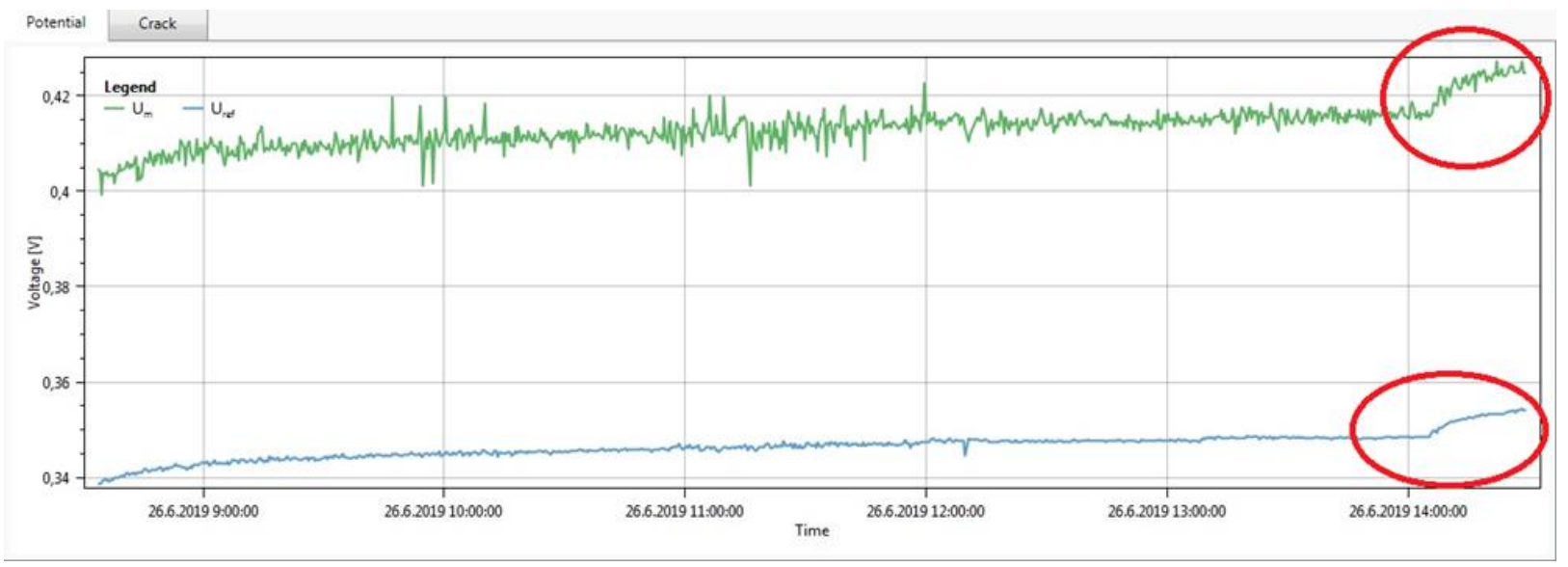

Figure 1 Onset of crack extension detected by potential method

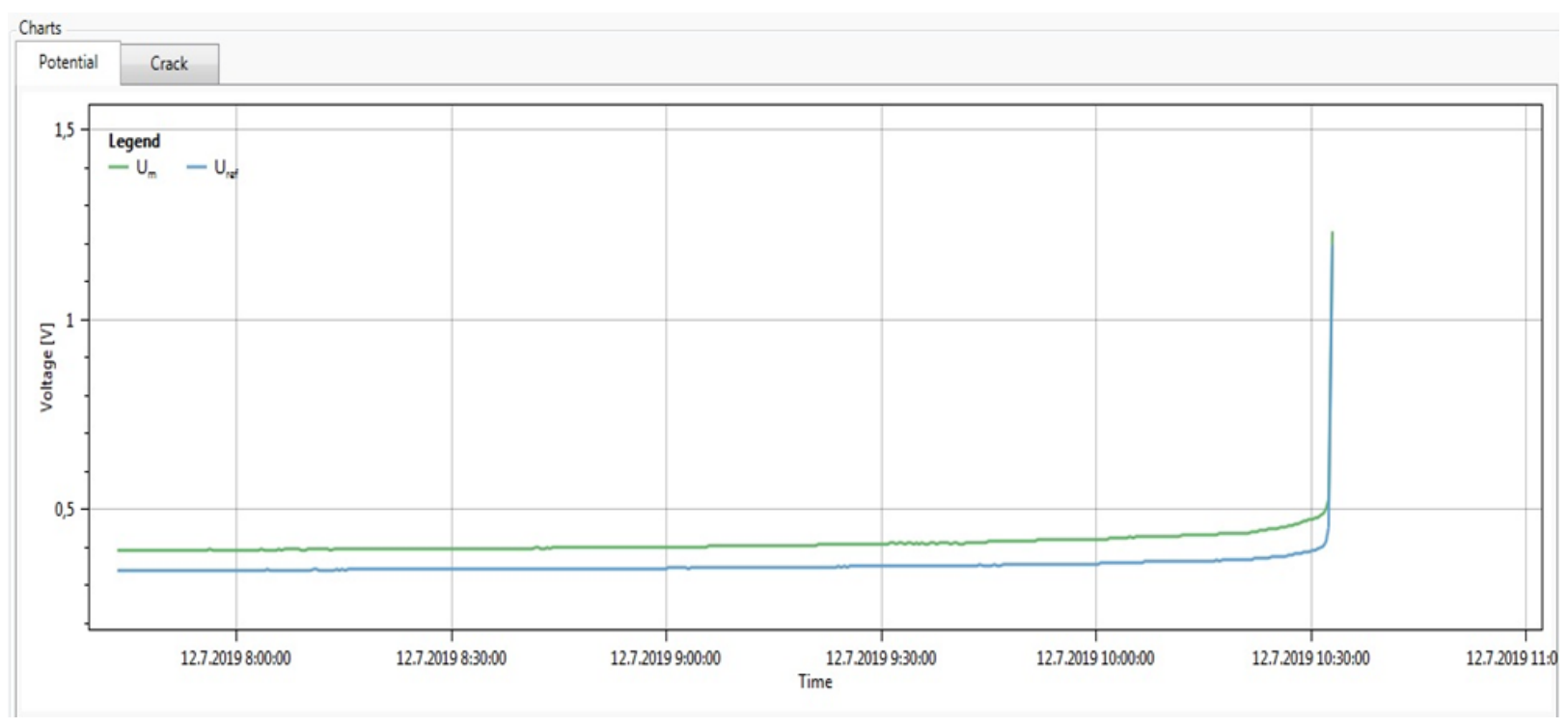

Figure 2 Unstable fracture detected by potential method 
After each test was measured initial crack and crack growth on fracture surface and final value of stress intensity factor was calculated.

\section{TEST RESULTS AND ITS DISCUSSION}

First specimen was tested in the air at room temperature according to ČSN EN ISO 12135 [4]. Notch opening displacement was measured on the front face of specimen. In Figure $\mathbf{3}$ is documented test record force vs. notch opening displacement. Specimen was loaded until maximum force was achieved. After unloading was specimen broken in liquid nitrogen and stable crack growth was measured on fracture surface

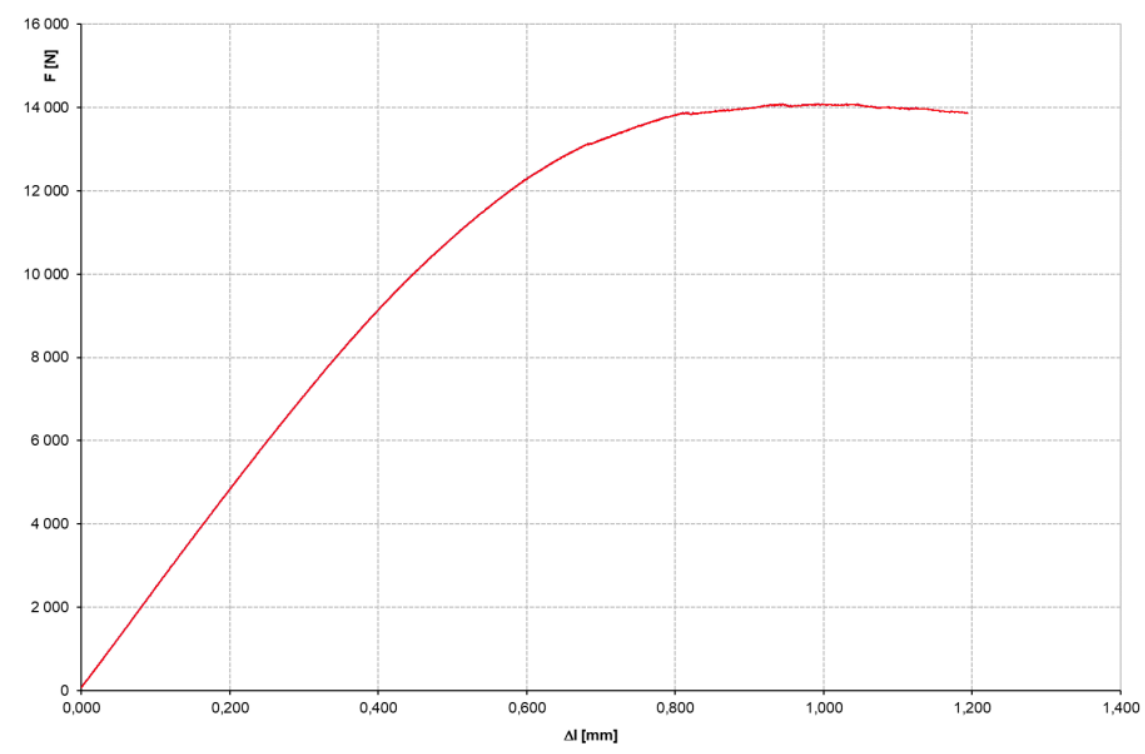

Figure 3 Test record of fracture toughness measurement in the air

From obtained data were calculated basic parameters of fracture toughness that are summarized in Table 1.

Table 1 Fracture toughness parameters of $34 \mathrm{CrMo} 4$ steel in the air at room temperature

\begin{tabular}{|c|c|c|c|}
\hline $\begin{array}{c}\text { Provisional fracture } \\
\text { toughness } \\
\mathrm{K}_{\mathrm{Q}}\left[\mathrm{MPa} \cdot \mathbf{m}^{\mathbf{1}}\right]\end{array}$ & $\begin{array}{c}\text { Stress intensity factor at } \\
\text { unloading } \\
\mathrm{K}_{\mathrm{Jc}}\left[\mathrm{MPa} \cdot \mathbf{m}^{1 / 2}\right]\end{array}$ & $\begin{array}{c}\text { Stress intensity factor at } \\
\text { maximum force } \\
\mathrm{K}_{\mathrm{Jcmax}}\left[\mathrm{MPa} \cdot \mathbf{m}^{\mathbf{1}}{ }^{2}\right]\end{array}$ & $\begin{array}{c}\text { Stable crack growth } \\
\Delta \mathbf{a}[\mathrm{mm}]\end{array}$ \\
\hline 83.2 & 312.5 & 283.2 & 0.72 \\
\hline
\end{tabular}

Fracture behavior of $34 \mathrm{CrMo} 4$ steel in the air is characterized by occurrence of ductile crack extension. Relatively high values of fracture toughness parameters testify to good resistance of studied material against unstable fracture and/or stable crack growth in the air.

For testing in high pressure hydrogen were used the same $C(T)$ specimens. Test conditions were described in chapter 2. Due to limited closed space into the autoclave were the tests carried out without sensor for notch opening displacement measurement. Taking into account test results analysis prescribed by standard [5], were the resultant values of stress intensity factors compiled on the base of equations for linear - elastic fracture toughness. Test results are summarized in Table 2.

Main test results, stress intensity factor at the time of failure, are possible to compare with test results obtained from fracture toughness in the air. From this comparison is clearly visible significant decrease of stress intensity factor in high-pressure hydrogen environment. In a simple approach may be concluded, that specimens loaded in hydrogen environment were broken and/or crack growth was observed at applied force at which was 
specimen loaded in the air still in linear-elastic area. Quite high scatter of resultant values was observed which may be related to heterogeneities in material microstructure.

Table 2 Fracture toughness results of 34CrMo4 steel in high pressure hydrogen environment

\begin{tabular}{|c|c|c|c|c|}
\hline Specimen ID & $\begin{array}{c}\text { Initial crack length } \\
\text { ao [mm] }\end{array}$ & $\begin{array}{c}\text { Stress intensity } \\
\text { factor at } \\
\text { unloading / fracture } \\
\text { Kmax }_{\left.\text {[MPa. } \mathbf{m}^{1 / 2}\right]}\end{array}$ & Failure type \\
\hline L1-A & 12.66 & 1.68 & 94.3 & stable crack growth \\
\hline L1-B & 12.84 & 1.56 & 52.1 & stable crack growth \\
\hline L1-C & 12.64 & - & 40.5 & unstable fracture \\
\hline L1-D & 12.71 & - & 50.8 & unstable fracture \\
\hline L1-E & 12.55 & - & 41.9 & unstable fracture \\
\hline L1-F & 12.77 & - & 38.3 & unstable fracture \\
\hline L1-G & 12.67 & 1.74 & 72.5 & stable crack growth \\
\hline L2-A & 12.85 & - & 70.5 & unstable fracture \\
\hline L2-B & 12.78 & - & 58.4 & unstable fracture \\
\hline L2-C & 12.68 & 1.12 & 71.9 & stable crack growth \\
\hline
\end{tabular}

For post-test examination were broken specimens subjected to analysis using scanning electron microscope. For this analysis were selected three representative examples.

Specimen L1-C was broken at low value of stress intensity factor $40.5 \mathrm{MPa} \cdot \mathrm{m}^{1 / 2}$. Fracture morphology taken by scanning electron microscope is documented in Figure 4. In Figure 4a is visible ragged fracture surface. At higher magnification was observed combination of transcrystalline and intercrystalline fracture (Figure $\mathbf{4 b}$ ).

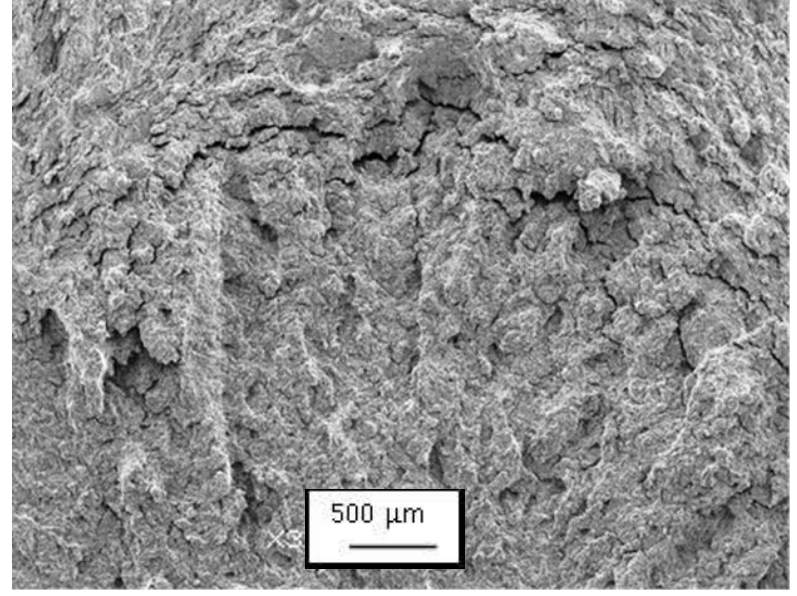

(a)

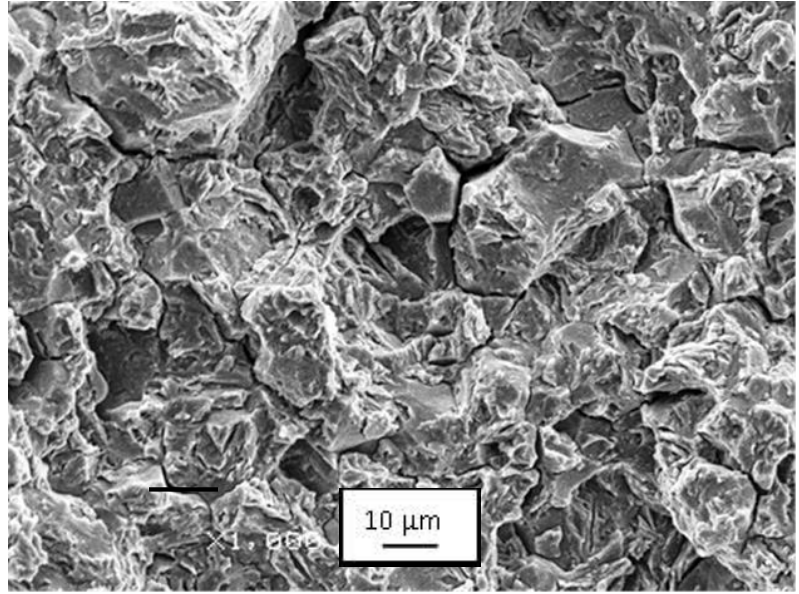

(b)

Figure 4 Fracture surface of specimen L1-C

Specimen L1-B was unloaded at stress intensity factor $52.1 \mathrm{MPa} \cdot \mathrm{m}^{1 / 2}$ after detection of crack growth by potential method. In this case was on fracture surface, more precisely in area of stable crack growth, observed combination of transcrystalline and intercrystalline fracture. In this case was portion of intercrystalline fracture higher. Fracture surface at higher magnification is shown in Figure 5. 


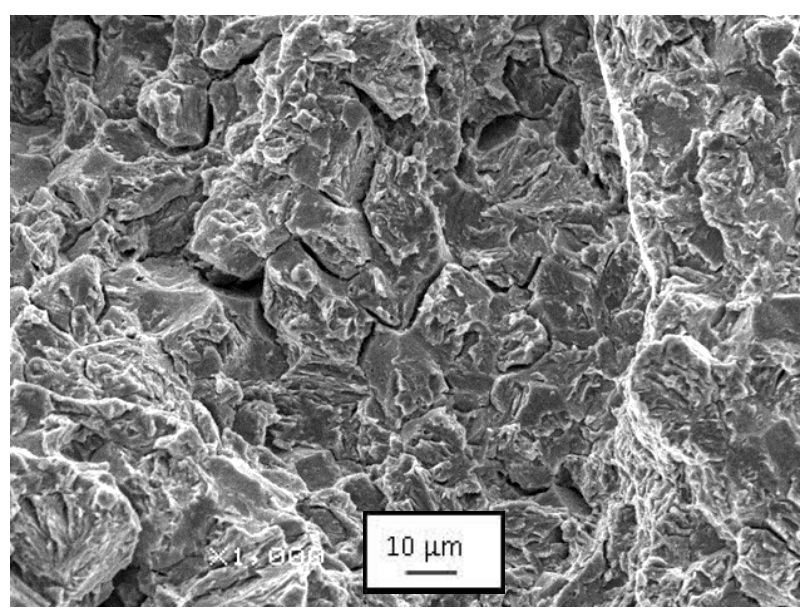

Figure 5 Fracture surface of specimen L1-B with predominant portion of intercrystalline fracture
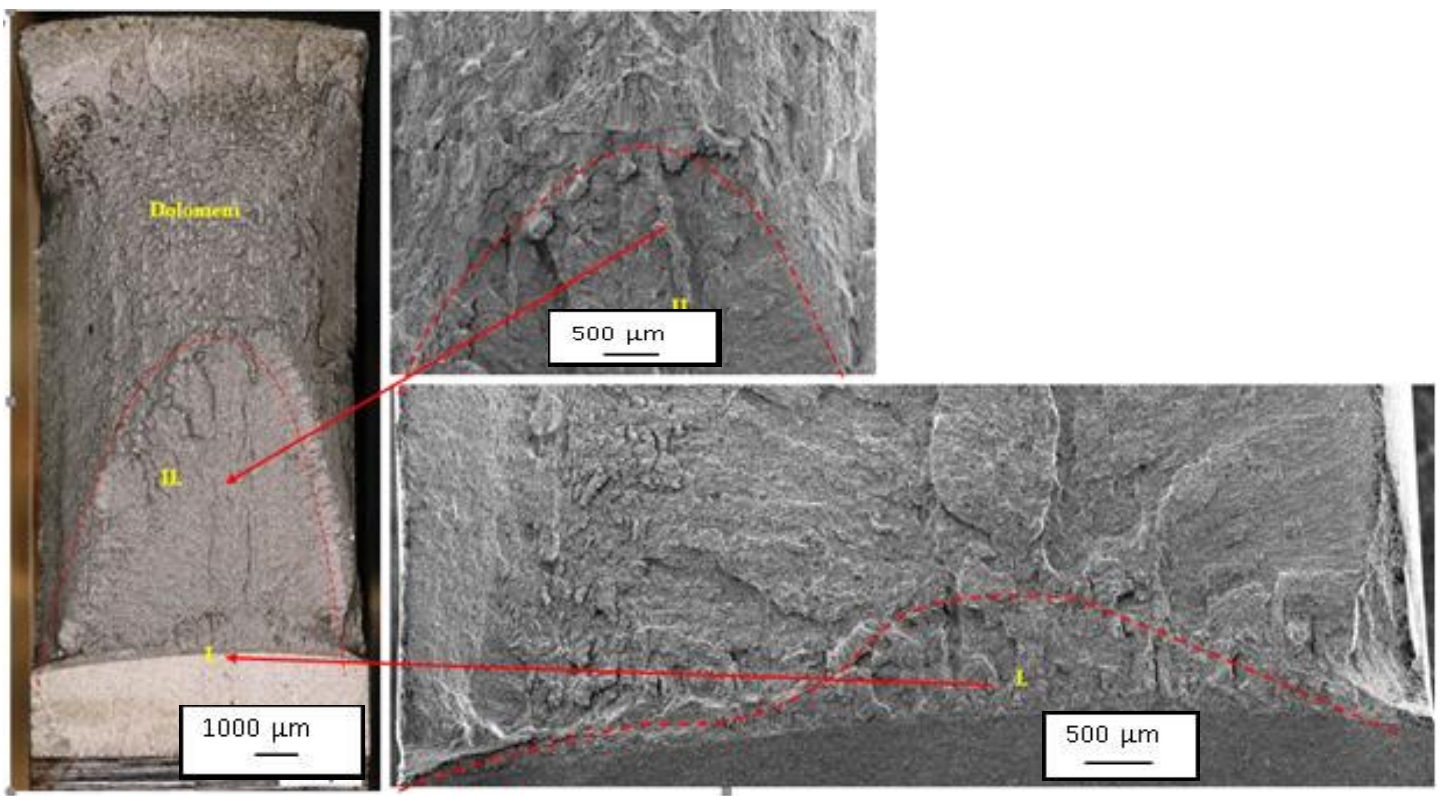

Figure 6 Fracture surface of L2-A specimen

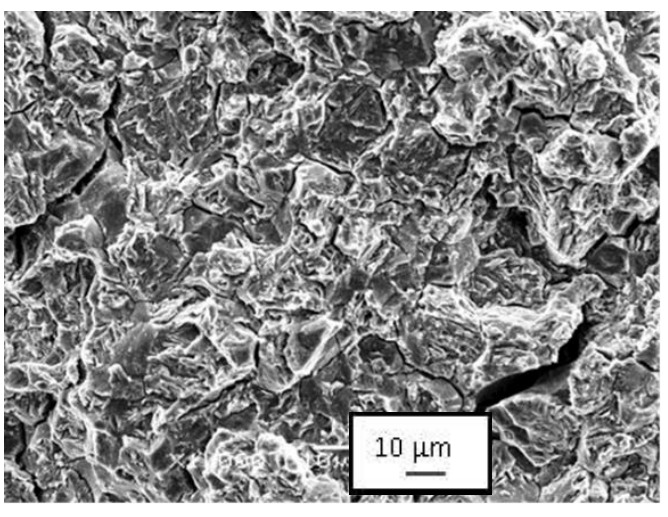

(a)

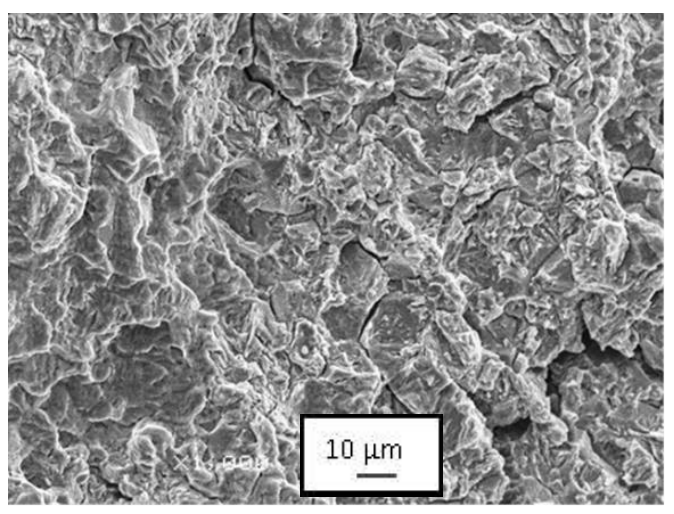

(b)

Figure 7 Fracture surface of specimen L2-A of (a) zone I and (b) zone II

Two different areas were observed on fracture surface of L2-A specimen that was broken at higher value of stress intensity factor $70.5 \mathrm{MPa} . \mathrm{m}^{1 / 2}$. Both areas, shown in Figure 6 were again created by combination of 
transcrystalline and intercrystalline fracture. Difference between these areas is higher number of transverse cracks in area adjacent to initial crack. Fracture surface of both areas is documented in Figure 7.

\section{CONCLUSIONS}

Experimental program was focused on evaluation of effect of high-pressure hydrogen environment on degradation of 34CrMo4 steel. Test conception was based on fracture toughness approach with the use of standard ČSN EN ISO 11114-4 which prescribes test methods for selecting materials for cylinders production. All tests were carried out in hydrogen autoclave with 0.5 I volume. Fracture behavior of $34 \mathrm{CrMo} 4$ steel in the air at room temperature is stable crack growth. This behavior is expected for this steel and is accompanied by higher values of fracture toughness parameters.

Significantly different fracture behavior was observed in hydrogen environment. In the case of all 10 specimens of two heats, which were used for testing, were stress intensity factors corresponding with crack growth or unstable fracture, very low. Exposure of loaded pre-cracked specimens in high pressure hydrogen leads to process of hydrogen embrittlement on the crack tip with consequent occurrence of intercrystalline fracture.

Test results confirm susceptibility of high strength steels to hydrogen embrittlement. Therefore manufacturing process of hydrogen cylinders is necessary to optimize from the point of view of metallurgical purity and heat treatment also for the purpose of reduction of hydrogen embrittlement effect.

\section{ACKNOWLEDGEMENTS}

This paper was created in the Project No. TK01030163 "Research and development of material characteristics needed for evaluation of reliability and lifetime of steels used for hydrogen industry" funded by the Technology Agency of The Czech Republic (TACR)

\section{REFERENCES}

[1] ČížEK, P., KANDER, L., KUBOŇ, Z. Effect of high-pressure hydrogen environment on fatigue properties of 34CrMo4 steel. In METAL 2019: 28 $8^{\text {th }}$ International Conference on Metallurgy and Materials. Ostrava: TANGER, 2019, pp. 626-631.

[2] SOJKA, J. Odolnost ocelí vůči vodíkové křehkosti. Ostrava: VŠB-TU Ostrava, 2007.

[3] O 11114-4: 2018 Transportable gas cylinders - Compatibility of cylinder and valve materials with gas contents Part 4: The test methods for selecting metallic material resistant to hydrogen embrittlement, 2018.

[4] ISO 12135:2018: Metallic materials - Unified method of test for the determination of quasistatic fracture toughness, 2018.

[5] KOREC, L. Odečítací jednotka pro měření potenciálovou metodou Techlab SRT-4K. Praha: Techlab, 2007. 